\title{
Comparison of flow resistance relations for debris flows using a one-dimensional finite element simulation model
}

\author{
D. Naef ${ }^{1, *}$, D. Rickenmann ${ }^{1,2}$, P. Rutschmann ${ }^{3}$, and B. W. McArdell ${ }^{1}$ \\ ${ }^{1}$ WSL Swiss Federal Research Institute, Dept. of Natural Hazards, 8903 Birmensdorf, Switzerland \\ ${ }^{2}$ BOKU University of Natural Resources and Life Sciences, Institute of Mountain Risk Engineering, 1190 Vienna, Austria \\ ${ }^{3}$ University of Innsbruck, Institute of Hydraulic Engineering, 6020 Innsbruck, Austria \\ *now at: Emch+Berger AG, 3001 Bern, Switzerland
}

Received: 22 August 2005 - Revised: 19 December 2005 - Accepted: 19 December 2005 - Published: 27 February 2006

\begin{abstract}
This paper describes a one-dimensional finite element code for debris flows developed to model the flow within a steep channel and the stopping conditions on the fan. The code allows the systematic comparison of a wide variety of previously proposed one-phase flow resistance laws using the same finite element solution method. The onedimensional depth-averaged equations of motion and the numerical model are explained. The model and implementation of the flow resistance relations was validated using published analytical results for the dam break case. Reasonable agreement for the front velocities and stopping location for a debris-flow event in the Kamikamihori torrent in Japan can be achieved with turbulent flow resistance relations including "stop" terms which allow the flow to come to rest on a gently sloping surface. While it is possible to match the overall bulk flow behavior using relatively simple flow resistance relations, they must be calibrated. A sensitivity analysis showed that the shape of the upstream input hydrograph does not much affect the flow conditions in the lower part of the flow path, whereas the event volume is much more important.
\end{abstract}

\section{Introduction}

Debris flows are mixtures of flowing sediment and water showing flow behavior intermediate between clear-water flows and mass movements of solid material, introducing a complexity which is difficult to incorporate into computational models for practical applications. However there is a clear need for such models as hazard evaluation or mitigation-measure design tools because debris flows continue to cause significant damage in mountainous regions. The main goal of this paper is to describe the development

Correspondence to: D. Rickenmann

(dieter.rickenmann@boku.ac.at) and first tests of a debris flow simulation model which allows comparison of relatively simple single-phase flow resistance relations which are often used in engineering applications. The new model, DFEM-1D, is based on a finite element solution of the depth-averaged shallow water equations. A variety of flow resistance relations have been implemented, allowing for simulation of the spectrum of debris flows from granular (stony) to viscous to turbulent (muddy) debris flows (e.g. Takahashi, 2001), facilitating comparison within the exact same numerical solution framework. The model allows the use of detailed natural topography for comparison with complex field cases. Hungr (1995) also developed a model allowing to select a variety of rheological kernels using only one numerical scheme.

Although a number of numerical simulation models have been developed to describe the propagation and deposition behavior of debris flows, they have rarely been systematically compared with field data. Many models require specification of "rheological" material or "flow resistance" parameters. Sediment concentration and solid material properties are among the key elements influencing the rheological or flow resistance characteristics of debris flows (Pierson and Costa, 1987), which may vary during a given event. Generally, there are no independent procedures to directly determine representative bulk parameters (e.g. viscosity and yield strength) characterizing the solid-fluid mixture in models where the mixture is treated as a single phase. For example there are no methods to directly measure the viscosity of a solid-fluid mixture with coarser grains including gravels, cobbles and boulders (e.g. Contreras and Davies, 2000). As a result, the parameters need to be back-calculated or calibrated to match past field events, and they often represent mean values. Additionally, each existing model generally uses a different numerical technique to approximate the solution of the governing equations, providing an additional degree of uncertainty when comparing results. 
A practical problem is the selection of the appropriate flow resistance relation which describes the flow regime. A Bingham or Herschel-Bulkley approach assumes that the debris-flow material behaves as a viscoplastic fluid (Coussot, 1997). Applications assuming a grain-inertia flow regime involve uncertainties in defining an appropriate flow resistance value representing grain-collision losses, which have been determined only with the help of experiments under simplified conditions, typically using relatively uniform sediments (e.g. Takahashi, 1991). A real debris flow may show characteristics of a viscous flow, a granular flow or a more turbulent (muddy) type flow, even within one torrent channel (Arattano and Franzi, 2004). Material properties change within the wave, typically with large boulders at the front and more fluid towards the tail (e.g. Suwa, 1989). The limits between these flow regimes are difficult to determine in the field.

After describing the governing equations, we state the flow resistance relations implemented in the DFEM-1D code, and some aspects related to the numerical solution procedure. Model implementation is verified by comparing the model results with an analytical solution for a simple dam break problem. For a real debris flow event with velocity information along the flow path, model predictions using the different flow resistance relations were performed, and their suitability is discussed.

\section{Governing equations}

The St. Venant or shallow water equations have been successfully applied to both dam break wave propagation and debris flows (e.g. Jin and Fread, 1999; Hungr, 1995; Fraccarollo and Papa, 2000; Laigle and Coussot, 1997). In this work the continuity and momentum equations are written in the conservative form:

$$
\begin{aligned}
& w\left(\frac{\partial h}{\partial t}+\frac{\partial q}{\partial x}\right)=-p \frac{\partial w}{\partial x} \\
& w\left(\frac{\partial q}{\partial t}+\left(g h-u^{2}\right) \frac{\partial h}{\partial x}+2 u \frac{\partial q}{\partial x}\right) \\
& =w g h\left(-\frac{\partial z_{b}}{\partial x}-\operatorname{sgn}(u) S_{f}-\lambda_{a, p} \cos \alpha \frac{\partial h}{\partial x}\right)-u p \frac{\partial w}{\partial x}
\end{aligned}
$$

with unknowns the flow depth $h$, and the specific discharge per unit width $q$. The channel is assumed to have a rectangular cross section with variable width $w, g$ is the gravitational acceleration, $u$ the vertically averaged flow velocity and $z_{b}$ the vertical bottom coordinate of the channel bed. The first term within the brackets on the right hand side of Eq. (2) is the channel bed slope; the second term, $S_{f}$, the flow resistance term, is discussed in the following section; and the third term denotes the internal resistance (earth pressure), with the active or passive earth pressure $\lambda_{a, p}$ and the slope angle $\alpha$. The sgn (signum) operator is used to ensure that the flow resistance component is correctly accounted for on flow on adverse slopes. The third term is neglected for the simulations presented herein because preliminary simulations showed only minor influence on the overall flow velocity and depth for the field case presented here.

\section{Flow resistance relations}

The solid-fluid mixture of a debris flow is considered as a quasi-homogeneous fluid. Mathematical models and constitutive equations, or flow resistance relations proposed for the flow resistance term $S_{f}$ in Eq. (2), may be broadly separated into: (i) one-phase models which describe the flow resistance behavior of either the slurry of water and fine material or the entire fluid-solid mixture; (ii) two-phase models which consider both a fluid phase and a solid phase (e.g. Bozhinskiy and Nazarov, 2000; Iverson and Denlinger, 2001); and (iii) hybrid models which assume different layers or flow regions with their own flow resistance characteristics (e.g. Takahashi, 2000). We limit our discussion to one-phase approaches because our model was designed to facilitate a systematic comparison of single-phase flow resistance relations which are in widespread use. The flow resistance relations, as implemented in the DFEM-1D model, are listed in Table 1 to facilitate direct comparison.

Model concepts for "mud flows" (e.g. Johnson and Rodine, 1984; Costa, 1984) and for "stony debris flows" (Takahashi, 1991) describe flows with a considerable proportion of fine material and flows where the coarser particles dominate the flow behavior, respectively (see also Jan and Shen, 1997). Mud flows may also be described as a Newtonian or Bingham fluid in the laminar flow regime; a somewhat more general form is the Coulomb viscous relation (Johnson and Rodine, 1984):

$\tau=\tau_{y}+\mu_{B}\left(\frac{d u}{d z}\right)=\tau_{c}+\sigma \tan \phi+\mu_{B}\left(\frac{d u}{d z}\right)$

where $\tau=$ shear stress, $\tau_{y}=$ yield strength, $\tau_{c}=$ cohesive strength, $\sigma=$ solid density, $\phi=$ friction angle of the solid material, $\mu_{B}=$ Bingham viscosity, and $(d u / d z)=$ shear rate. The first three terms of Eq. (3) reflect the Bingham equation characterizing the laminar flow of a viscoplastic or Bingham fluid; when the yield strength $\tau_{y}$ is replaced by $\left(\tau_{c}+\sigma\right.$ tan $\phi)$, Eq. (3) describes a possible shear behavior of a granular solid material. A number of models are based on a rheologic formulation for a Bingham or viscoplastic fluid (e.g. Fraccarollo and Papa, 2000; Imran et al., 2001; Laigle and Coussot, 1997; Zanuttigh and Lamberti, 2004). Bingham-type relations included in our model are the standard cubic formulation (when expressed in terms of the resisting bed shear stress) (Table 1, Relation A). $\tau_{0}$ is defined as the bed shear stress in the flow. For a stress ratio $\tau_{y} / \tau_{0}$ smaller than 0.5 , neglecting the cubic term in the Bingham equation (Table 1, B) 
Table 1. Flow resistance terms.

\begin{tabular}{ccc}
\hline Descriptor & Flow resistance relation & Flow resistance term $S_{f}$ \\
\hline A & Full Bingham & $S_{f}=\frac{\tau_{0}}{\rho g h}$ \\
B & Simplified Bingham & $\tau_{0}$ can be determined by: $2 \tau_{0}^{3}-3\left(\tau_{y}+2 \frac{\mu_{B} q}{h^{2}}\right) \tau_{0}^{2}+\tau_{y}^{3}=0$ \\
C & Voellmy & $S_{f}=\frac{\tau_{0}}{\rho g h}$ with $\tau_{0}^{=} 1.5 \tau_{y}+3 \frac{\mu_{B} q}{h^{2}}$ \\
D & Turbulent \& Coulomb & $S_{f}=\frac{q \sqrt{q^{2}}}{h^{2} C^{2} h_{r}}+\cos \alpha \tan \delta$ \\
E & Turbulent \& Yield & $S_{f}=\frac{n^{2} q \sqrt{q^{2}}}{h^{2} h_{r}^{4}}+\cos \alpha \tan \delta$ \\
F & Turbulent, Coulomb \& yield & $S_{f}=\frac{n^{2} q \sqrt{q^{2}}}{h^{2} h_{r}^{4}}+\frac{\tau_{y}}{\rho g h}$ \\
& & $S_{f}=\frac{n^{2} q \sqrt{q^{2}}}{h^{2} h_{r}^{4}}+\frac{\tau_{i}}{\rho g h}$ \\
G & Quadratic & with $\tau_{i}=\min \left(\tau_{y} ; \rho g \cos \alpha \tan \delta\right)$ \\
H & Coulomb viscous & $S_{f}=\frac{n^{2} q \sqrt{q^{2}}}{h^{2} h_{r}^{3}}+\frac{\kappa \eta q}{8 h^{3} \rho g}+\frac{\tau_{y}}{\rho g h}$ \\
\hline
\end{tabular}

leads to an error in the mean velocity less than 6.3\% (Rickenmann, 1990). Rheologic investigations of debris-flow slurries suggest that the Herschel-Bulkley model should be preferred over the Bingham model, because the former is more general and can better describe the fluid behavior particularly at low shear rates (Ancey and Jorrot, 2001; Coussot, 1997; Malet et al., 2003). However this model introduces additional terms which need to be either calibrated or measured and has not yet been implemented in the DFEM-1D model. For large flow velocities a debris flow may show turbulent behavior, suggesting that laminar flow resistance relations such as Eq. (3) may be inappropriate (Rickenmann, 1999).

For coarse-grained or granular debris flows where grain collisions dominate the flow behavior, the dilatant-inertial grain-shearing relation (Takahashi, 1991) has been proposed:

$\tau=\xi\left(\frac{d u}{d z}\right)^{2}$

where $\xi$ is a function of grain size, solid concentration, particle density, and dynamic angle of internal friction. The flow regimes defined by these two equations are referred to as grain-inertia (Eq. 4) and macroviscous (Eq. 3), and they can be distinguished by the dimensionless "Bagnold" number (Takahashi, 2000, 2001). The grain-inertia relation in the form of Eq. (4) does not allow the flow to stop on a nonhorizontal slope. Examples of models based on variations of Eq. (4) include Brufau et al. (2000); Nakagawa and Takahashi (1997); Shieh et al. (1996); and Takahashi (1991). The sediment concentration may be used to distinguish between dominant flow regimes (e.g. Takahashi, 2000, 2001), as for example between inertial grain flow ("stony debris flow"), a transitional stage ("immature debris flow"), and turbulent flow ("muddy debris flow"). A dilatant inertial relation can be used in our model when grain shearing processes dominate the flow behavior.

The turbulent flow regime is a third basic regime for debris flows for cases where turbulent stresses dominate the flow behavior (Takahashi, 2000). Successful applications of the Manning-Strickler turbulent resistance relation include debris-flow simulations by Jin and Fread (1999) and Rickenmann and Koch (1997). A disadvantage of this approach is that it cannot reproduce the cessation of motion on gently sloping surfaces. Nevertheless, Costa (1997) and Jin and Fread (1999) showed that the flow depth and the velocity of debris flows, can be simulated reasonably well within the channel, after calibration of appropriate pseudo Manning $n$ values. For many natural debris flows both mean grain size and solid concentration tend to decrease upstream of the front, suggesting that the flow may become either turbulent or viscous upstream of the front.

Several refinements have been proposed for these three basic flow regimes, partly to overcome the shortcomings of each flow regime and to account for the fact that a debris flow may change from one regime to another within the same flow. Within one flow, the Reynolds number can be used to distinguish between the turbulent and laminar regimes, while the relative flow depth $h / d$ can be used to distinguish between the turbulent and grain-inertia regime (where $h$ is flow depth and $d$ is particle size). Empirical evidence suggests that grain-inertia cannot be dominant when $h / d$ exceeds about 20-30 (Julien, 1997; Hashimoto, 1997; Takahashi, 2000). Chen (1988) proposed a generalized viscoplastic model which combines both approaches represented by Eqs. (3) and (4). Additive combinations of the three basic flow regimes have also been proposed, for example Julien and Lan (1991) account for dispersive and turbulent stress with a lumped coefficient and combine it 
with a Bingham approach. The Bingham model has also been extended in other studies by the addition of a flow resistance term to account for channel roughness and turbulence (Han and Wang, 1996; Jin and Fread, 1999). The commercially available two-dimensional flood and mudflow simulation program, FLO-2D (O'Brien et al., 1993) is based on the so-called "quadratic" rheologic approach proposed by Julien and Lan (1991), combining yield, viscous, collision, and turbulent stress components. The Bingham parameters $\tau_{y}$ and $\mu_{B}$ are defined as exponential functions of sediment concentration which may vary over time. The FLO-2D model has been often used for application to natural debris flows or for comparison with other models (e.g. Chuang et al., 2000; Ghilardi et al., 2000; Hübl and Steinwendtner, 2000).

Several of these "additive" relations, including turbulent relations and various terms which can describe the stopping of a flow on a sloping surface, have been implemented in DFEM-1D. The Voellmy flow relation (Table 1, C) consists of a turbulent Chézy term, $C$, accounting for velocitydependent friction losses, and a Coulomb or basal friction term to describe the stopping mechanism, where the basal friction angle $\delta$ is typically only a fraction of the Coulomb angle $\phi$ (McDougall and Hungr, 2006). It has been successfully applied to debris flows (Rickenmann and Koch, 1997; Jakob et al., 2000; Hürlimann et al., 2003; Revellino et al., 2004) and other geophysical flows of granular material (Bartelt et al., 1999; Chen and Lee, 2003; Crosta et al., 2004). The combination of the Coulomb friction term or a yield stress term with a turbulent flow resistance relation (Table 1, D or E, respectively) can similarly be used. Implementation of turbulent Manning-Strickler formulation combined with the minimum of the Coulomb or the yield stress (Table 1, F) allows flow even during very small flow depths as observed at the tail of a debris flow. A combination of resistance flow terms as used in the commercial code FLO2D (O'Brien et al., 1993) includes turbulent-collisional, yield stress and laminar flow resistance terms in the "quadratic" rheologic law (Table 1, G). The Coulomb viscous flow relation (Table 1, H) combines the Bingham laminar relation with a differently defined yield stress $\tau_{y}$ using a Coulomb friction term.

\section{Numerical approach}

The finite element model, DFEM-1D, is based on the FEMTOOL software, a finite element toolbox developed at the Laboratory for Hydraulics, Hydrology and Glaciology at the Swiss Federal Institute of Technology, Zurich (Rutschmann, 1993). FEMTOOL allows for the implementation of any single or system of partial differential equations and uses a standard Galerkin approach. Time is also treated in a finite element way and therefore 2-D space/time finite elements are used. Even though computationally expensive, such elements are advantageous for convection dominated flows (Rutschmann, 1993). Furthermore it allows for shifting nodes between time steps in a Lagrangian way to facilitate front tracking, however this feature has not yet been exploited in the DFEM-1D model. The FEMTOOL software allows any order of shape function, but only linear elements are used in this paper. The weighted equations are integrated using numerical integration by a 3 point Gaussian integration technique. Linearization is performed using a Picard iteration with a relative convergence criterion set to $1 \times 10^{-8}$. The relative convergence is set to the ratio of improvement between old and new iteration normalized by the average value of the corresponding variable.

The shallow water equations were implemented in the toolbox for the 1-D case by Rutschmann (1994) and for the 2D case by Naef (1997). To increase the numerical stability an upwind scheme following Katopodes (1984) is introduced.

An accurate description of the wet-dry transition at the debris flow front is essential for modeling. Problems arise when the flow depth approaches zero and the flow resistance term increases infinitely, leading to an unrealistically high resistance and, in the limiting case, a division by zero. To maintain stability a minimum cutoff depth is introduced. Whenever the flow depth is smaller than a threshold value $h_{\min }$, the discharge in the momentum equation is set to zero and the depth is set to the minimum value. Tests for typical flow conditions showed that with a limiting depth of $0.01 \mathrm{~m}$ stable and accurate results can be achieved. For mass conservation related to the extremely small error introduced by moving the front between nodes, the volume is checked and if necessary adjusted after each time step.

To stabilize the solution downstream of the wave front for certain flow relations, we assume that the flow resistance loss cannot be larger than the available kinetic energy, and that the flow resistance is unable to change the sign of the velocity within one time step (e.g. Bechteler et al., 1994; Nujic, 1995). Alternative stabilization procedures, not implemented in our model, include a limiting value of a turbulent Chézy coefficient for a laminar flow resistance relation (Zanuttigh and Lamberti, 2004; McArdell et al., 2003) and a weighted average of the flow depth to increase damping of local peak which may result in numerical instabilities (Koch, 1998).

\section{Model verification}

Comparison with an analytical solution tests the implementation of the equations and the numerical solution scheme. Hungr (1995) gives a solution for a plastic fluid based on an approximated energy solution for a horizontal dam break problem consisting of a horizontal flow bed with a dam located at $x=305 \mathrm{~m}$ and a height of $30.5 \mathrm{~m}$. The downstream bed is initially dry and the dam is removed instantaneously; 500 linear elements of $5 \mathrm{~m}$ length were used. A stopping location of $x=1896 \mathrm{~m}$ results under Hungr's assumptions for yield stress and density. 
Table 2. Flow resistance parameters used for simulation of dam break problem.

\begin{tabular}{ll}
\hline Flow relation & Flow resistance parameter \\
\hline Turbulent \& Yield & $n=1 . \mathrm{e}-10 \mathrm{~s} / \mathrm{m}^{1 / 3}, \tau_{y}=2390 \mathrm{~N} / \mathrm{m}^{2}, \rho=1835 \mathrm{~kg} / \mathrm{m}^{3}$ \\
Turbulent, Coulomb \& yield & $n=0.0667 \mathrm{~s} / \mathrm{m}^{1 / 3}, \delta=10^{\circ}, \tau_{y}=500 \mathrm{~N} / \mathrm{m}^{2}, \rho=1835 \mathrm{~kg} / \mathrm{m}^{3}$ \\
Quadratic & $n=0.02 \mathrm{~s} / \mathrm{m}^{1 / 3}, \tau_{y}=1500 \mathrm{~N} / \mathrm{m}^{2}, \rho=1835 \mathrm{~kg} / \mathrm{m}^{3}, \eta=100 \mathrm{~Pa} \cdot \mathrm{s}, \kappa=24$ \\
Full Bingham & $\mu_{B}=100 \mathrm{~Pa} \mathrm{~s}, \tau_{y}=1500 \mathrm{~N} / \mathrm{m}^{2}, \rho=1835 \mathrm{~kg} / \mathrm{m}^{3}$ \\
Simplified Bingham & $\mu_{B}=100 \mathrm{~Pa} \cdot \mathrm{s}, \tau_{y}=1500 \mathrm{~N} / \mathrm{m}^{2}, \rho=1835 \mathrm{~kg} / \mathrm{m}^{3}$ \\
Coulomb viscous & $\delta=1.2^{\circ}, \mu_{B}=5.0 \mathrm{~Pa} \mathrm{~s}, \rho=1835 \mathrm{~kg} / \mathrm{m}^{3}$ \\
\hline
\end{tabular}

For the case of a plastic fluid (here approximated by flow law $\mathrm{E}$ in Table 1 with a very small turbulent flow resistance, see also Table 2), the results for runout distance (Fig. 1a) show a good agreement with the theoretical solution. With the Coulomb viscous relation (Fig. 1b), the final profile is too flat and too much material remains in the upstream basin in comparison with the analytical solution. The run time until stopping occurs varies by about a factor of 4 between the fastest and the slowest model. For the Voellmy and turbulentCoulomb relations (not displayed in Fig. 1), a small turbulent flow resistance term results in increased runout distances and flatter deposition angles. Simulations containing a large turbulent flow resistance term have steeper deposition angles corresponding to shorter runout distances, eventually approaching the dry friction angle. The dilatant and Newton-laminar flow resistance relations are also not displayed in Fig. 1, since they do not stop under the above conditions.

A comparison with the DAN model from Hungr (1995) for a horizontal break of a tailings dam, as solved for the analytical case described above, shows only minor differences between the two models, suggesting that the numerical scheme is sufficient for solving the underlying equations.

Our model has also been applied to a snow avalanche using the Ariefa test case given in the Swiss Avalanches Guidelines, and the results agree with the AVAL-1d simulations of Bartelt et al. (1999), which uses a Voellmy fluid model including an active/passive earth pressure term. Hürlimann et al. (2003) used the AVAL-1d code to help interpret debris flow observations from the Swiss alps. Simulations with the AVAL-1d model, including identical coefficients, topography, and initial conditions, showed very similar results to those from the DFEM-1D model.

\section{Comparison with field data}

The calculations presented here are for the 3 August 1976 debris flow event at the Kamikamihori valley in Japan (Okuda et al., 1980; Suwa and Okuda, 1983). The front velocity is reported for 10 reaches, the location of the deposition front is at $x=2225 \mathrm{~m}$, and a hydrograph for the discharge and velocity is reported for the middle reach. At the Kamikamihori
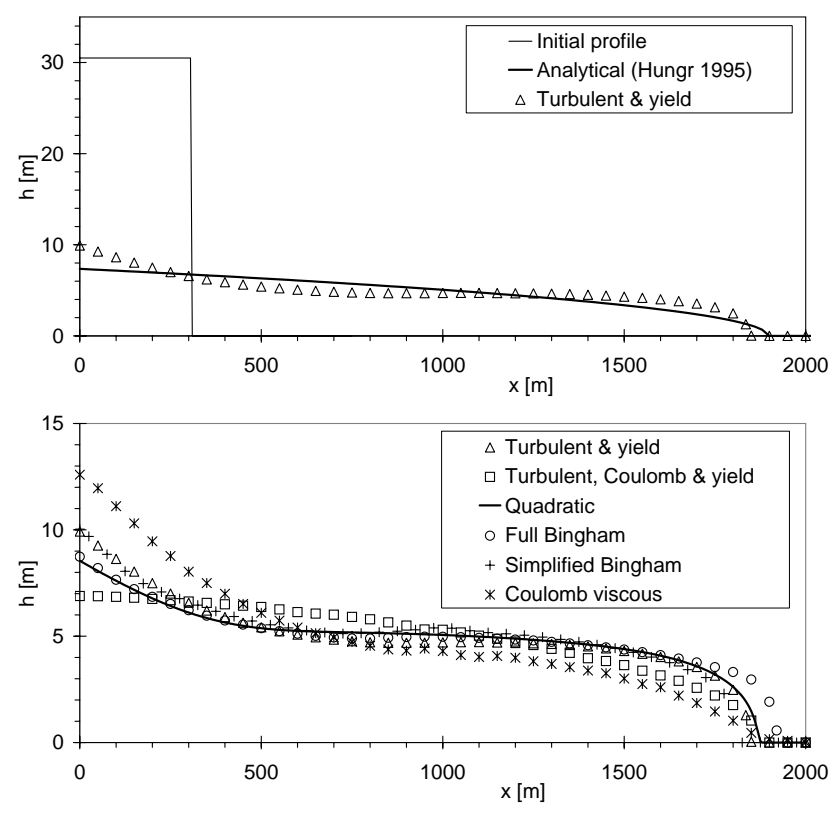

Fig. 1. Simulation of dam break case, showing flow depth and stopping location for various flow resistance relations. Top panel: comparison of analytical solution with flow law E (Table 1), bottom panel: comparison of several other flow laws from Table 1.

valley, debris flows generally have a higher concentration of large boulders and close to the debris-flow front whereas the rear part of the flow contains more fine material. In some cases, the first, large surge is followed by a number of smaller surges, presumably roll-waves.

For the simulation a grid with five meter long linear elements is used. The channel width is set to $10 \mathrm{~m}$, below the fan apex $(x=1900 \mathrm{~m})$ the channel widens to $15 \mathrm{~m}$ over a distance of $100 \mathrm{~m}$, after which an additional increase in width of $10 \mathrm{~m}$ per $100 \mathrm{~m}$ channel length is assumed (Fig. 2). The longitudinal profile is a high order polynomial fit to the measured profile, as used by Rickenmann and Koch (1997). The input at $x=0 \mathrm{~m}$ consists of a triangular-shaped hydrograph, the specific discharge increases from 0 to $20 \mathrm{~m}^{2} \mathrm{~s}^{-1}$ and the flow depth from 0 to $2.75 \mathrm{~m}$ over the first $10 \mathrm{~s}$, and both return to zero at $64 \mathrm{~s}$, corresponding to a maximum input flow 


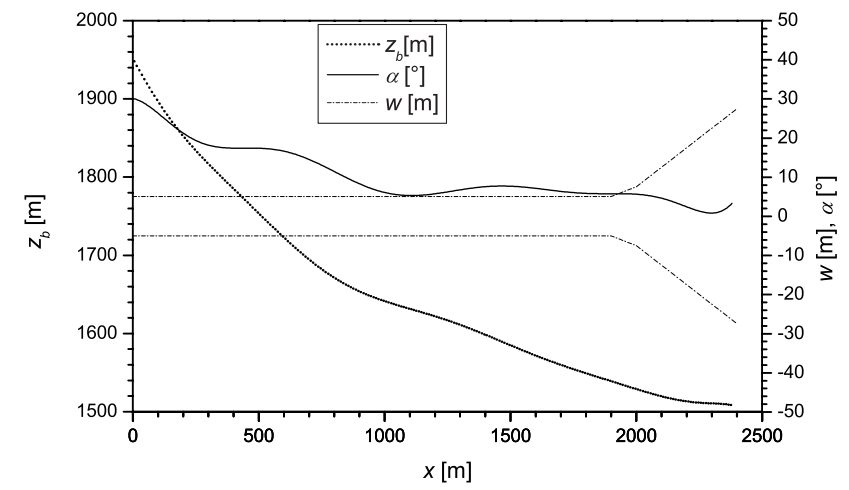

Fig. 2. Initial conditions for simulation of the 3 August 1976 event at the Kamikamihori valley.

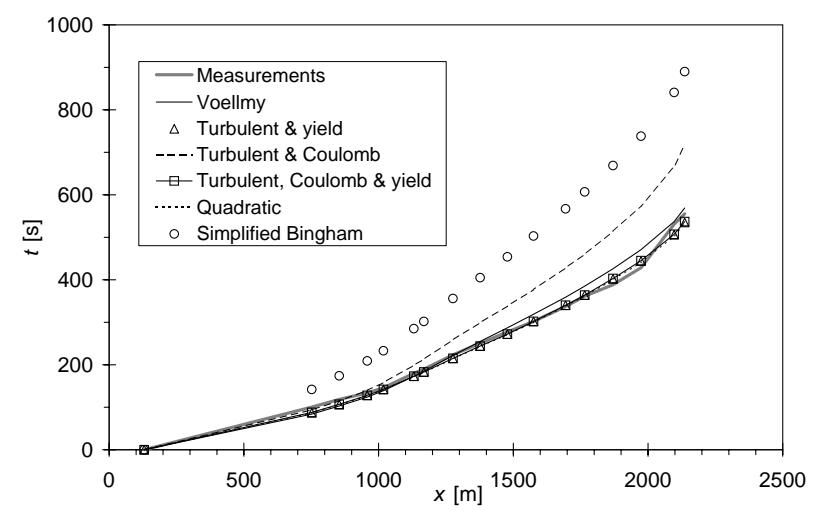

Fig. 3. Measured and simulated front trajectories for the Kamikamihori case. Note that except for the Simplified Bingham and the Quadratic model, the results of the other models more or less collapse with the measurements.

velocity of about $7.3 \mathrm{~ms}^{-1}$ and a total volume of $6400 \mathrm{~m}^{3}$. This volume matches the observed one, and the input flow parameters are assumed to be plausible for a channel steepness of about $40^{\circ}$. The focus of our simulations was on reproducing the flow behavior of the first, large surge of the debris flow event.

The model was repeatedly run and the flow resistance coefficients incrementally adjusted to match the runout distance and the reach-wise velocity. Mixture density was held constant for the different flow resistance approaches. In the "quadratic" model, a standard value of $\kappa=24$ is assumed. Thus only two parameters are varied for the majority of the models, while three parameters are varied for models $\mathrm{F}$ and G.

The front location for models that include a turbulent flow resistance term show good agreement with field data (Fig. 3). In the middle section all the models slightly underestimate the velocity of the debris flow (Fig. 4). The dilatant, Newton laminar, and other laminar Bingham-type flow resistance relations show instabilities (e.g. large velocity fluctuations) in

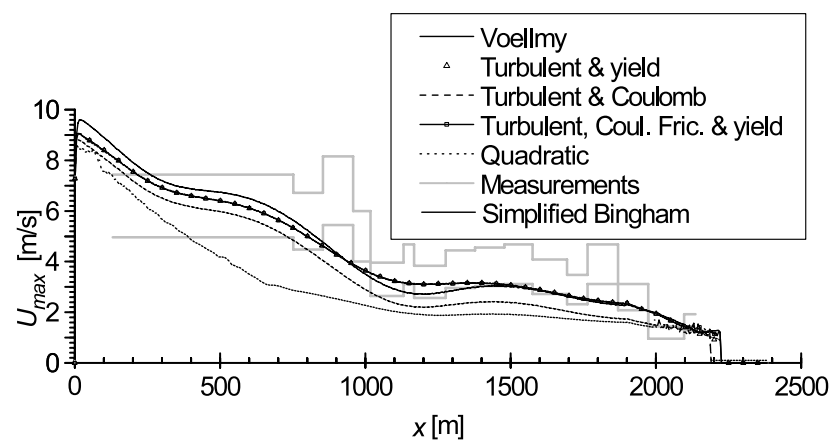

Fig. 4. Comparison of reachwise velocities for the Kamikamihori case. Field values include an assumed variation of $+/-20 \%$.

the steep upstream channel reach with large velocities, and in the slower part of the flow the kinetic energy limitation, discussed above, controls the flow behavior for these flow relations; therefore only the simulations results of the simplified Bingham law are shown. The location where the debris flow stopped can be reasonably matched for all flow resistance relations which include a "stop" term with appropriate values. The best-fit flow resistance coefficients are summarized in Table 3.

Sensitivity to peak input discharge was investigated in a series of simulations with peak discharges from 10 to $60 \mathrm{~m}^{2} \mathrm{~s}^{-1}$, using the Voellmy flow resistance relation and holding the event volume constant. The results (Fig. 5) indicate that the model is sensitive to the input hydrograph, but that the differences gradually disappear and are similar at a distance of $\mathrm{x}=1100 \mathrm{~m}$ because the flows with a larger unit discharge attenuate more rapidly than flows with a smaller peak discharge. Results using the input hydrograph represented as a "landslide" block hydrograph (thickness $=2.5 \mathrm{~m}$, initial velocity $=6.5 \mathrm{~ms}^{-1}$ ) show similar final results as the triangularshaped input hydrograph (Fig. 5). A steep hydrograph with only a third of the volume does not provide enough volume to maintain a constantly high flow and results in a more upstream stopping location, in agreement with expectations of shorter travel distances for smaller debris flows.

A comparison of the velocity and flow depth and along the flow path (Fig. 6) provides some insight on the behavior of the model. The velocities and flow depths used in Fig. 6 correspond to the occurrence of the maximum flow depth at any given channel location. The flow resistance relations shown here include the Voellmy fluid, Bingham fluid, and the quadratic approach (Table 1, C, B, and G, respectively). The general trend for all three flow resistance relations is for quasi-uniform flow to develop along the upper $300 \mathrm{~m}$ reach of the channel, followed downstream by a correlation of flow resistance behavior with the local channel slope. Downstream of the fan apex (near $\mathrm{x}=1900 \mathrm{~m}$ ) the channel progressively widens, causing the flow to spread laterally and the flow depth to decrease. The maximum flow velocities are 
Table 3. Flow resistance parameters used for simulation of the 3 August 1976 Kamikamihori event.

\begin{tabular}{lll}
\hline Flow relation & Flow resistance parameter & Stop location $x$ [m] \\
\hline Voellmy & $C=10.95 \mathrm{~m}^{1 / 2} / \mathrm{s}, \delta=3.5^{\circ}$ & 2220 \\
Turbulent \& Coulomb & $n=0.111 \mathrm{~s} / \mathrm{m}^{1 / 3}, \delta=3.5^{\circ}$ & 2185 \\
Turbulent \& Yield & $n=0.111 \mathrm{~s} / \mathrm{m}^{1 / 3}, \tau_{y}=300 \mathrm{~N} / \mathrm{m}^{2}, \rho=2000 \mathrm{~kg} / \mathrm{m}^{3}$ & 2240 \\
Turbulent, Coulomb \& yield & $n=0.111 \mathrm{~s} / \mathrm{m}^{1 / 3}, \delta=3.5^{\circ}, \tau_{y}=300 \mathrm{~N} / \mathrm{m}^{2}, \rho=2000 \mathrm{~kg} / \mathrm{m}^{3}$ & 2220 \\
Quadratic & $n=0.111 \mathrm{~s} / \mathrm{m}^{1 / 3}, \tau_{y}=200 \mathrm{~N} / \mathrm{m}^{2}, \rho=2000 \mathrm{~kg} / \mathrm{m}^{3}, \eta=10 \mathrm{~Pa} \mathrm{~s}, \kappa=24$ & 2230 \\
Simplified Bingham & $\mu_{B}=3200 \mathrm{~Pa} \mathrm{~s}, \tau_{y}=200 \mathrm{~N} / \mathrm{m}^{2}, \rho=2000 \mathrm{~kg} / \mathrm{m}^{3}$ & 2185 \\
\hline
\end{tabular}

similar for the quadratic and Voellmy flow resistance relations and mainly reflect the influence of the channel slope, being larger for steeper reaches. The increase in depth over reaches with a relatively gentle slope sections is more pronounced for the Voellmy than for the quadratic flow resistance relation. At the stopping location, for the Voellmy relation the material accumulates and the flow depth increases; in contrast, the simplified Bingham relation results in a continually decreasing flow depth. The general reduction of the flow depth along the flow path is mainly related to the elongation of the wave. The Froude number is always less than 1 for the Bingham relation, while for the Voellmy and quadratic relations, the flow is initially supercritical upstream, slightly subcritical in the middle reach, and the Froude number decreases to about 0.5 on the depositional reach.

A comparison of the relative magnitude of the flow resistance terms along the flow path is shown in Fig. 6. The relative flow resistance is defined here as the proportion of each term in the equations (Table 1) to the total flow resistance slope $S_{f}$. For the Voellmy and quadratic flow resistance relation, the sum of the flow resistance terms is smaller or equal to the (gravitational) slope term on the right-hand side of Eq. (2). The flow resistance terms for the simplified Bingham flow resistance relation are much larger than the slope term and are consequently limited by the kinetic energy approach described above. Over the steep channel section with a slope of about 0.3, the turbulent Chézy term in the Voellmy relation contributes about $80 \%$ to the total flow resistance; the two terms are nearly equal on a slope of 0.12 . For the Voellmy fluid, the basal friction angle $\delta$ appears to significantly contribute to the total resistance when channel slope angles are about $2 \delta$ or less. At the location with the largest flow depth (about $x=2150 \mathrm{~m}$ ), the slope angle and the basal friction angle are equal; at this point, the contribution by the basal friction term clearly dominates the flow resistance behavior over the remainder of the flow path. In comparison, the turbulent-dispersive (Manning) term in the quadratic relation dominates, comprising more than $85 \%$ of the total flow resistance. The remaining flow resistance is comprised of a 2:1 ratio of the yield stress and viscosity terms. On the downstream part of the fan, the shear stress term contribution rapidly increases to $50 \%$ of the total flow resistance. For

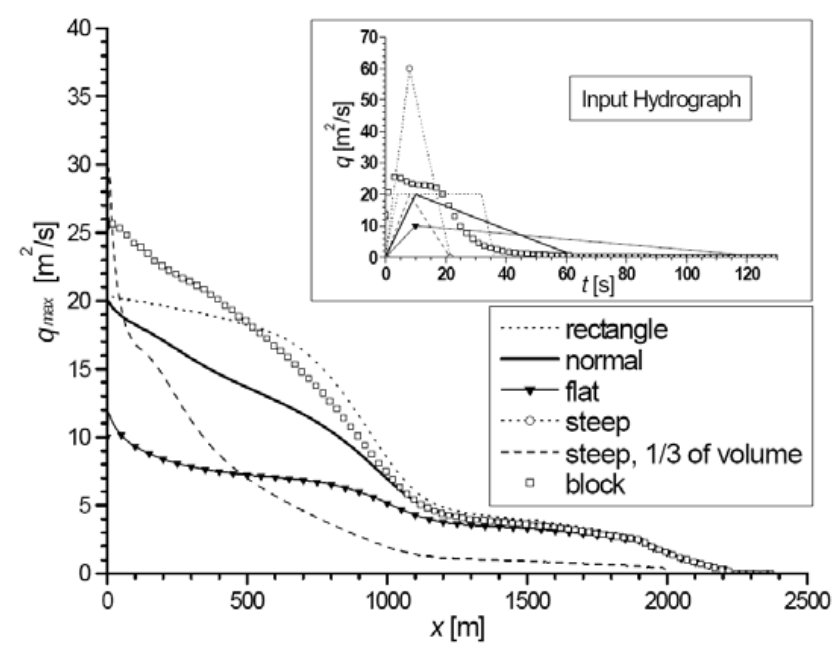

Fig. 5. Influence of input hydrograph on the simulated maximum specific discharge for Voellmy flow resistance relation.

the Voellmy and quadratic flow relations, the sum of the resistance terms is generally the same as the slope term, with exceptions very near to the front and for the stopping conditions towards the upstream end of the wave. This implies that the bulk behavior of the debris-flow wave can be closely approximated by uniform flow conditions.

For the Simplified Bingham relation only the values contributing to the basal shear stress are compared. The flow resistance is dominated by the Bingham viscosity alone, and the yield stress term never exceeds $5 \%$ of the total flow resistance. For flow depths much smaller than $1 \mathrm{~m}$, the influence of the viscosity term is even more pronounced because there is an $h^{2}$ dependency in the denominator. The discussion of the Simplified Bingham relation is complicated by the fact that the flow resistance terms, as displayed, are adjusted to keep them smaller or equal to the available kinetic energy. However it is clear that the influence of the Bingham yield stress can almost be neglected for the upstream and middle reaches.

The combined turbulent - yield stress relation (Table 1, E) behaves similarly to the quadratic approach (Table 1, G); however the yield stress term alone represents the stopping 


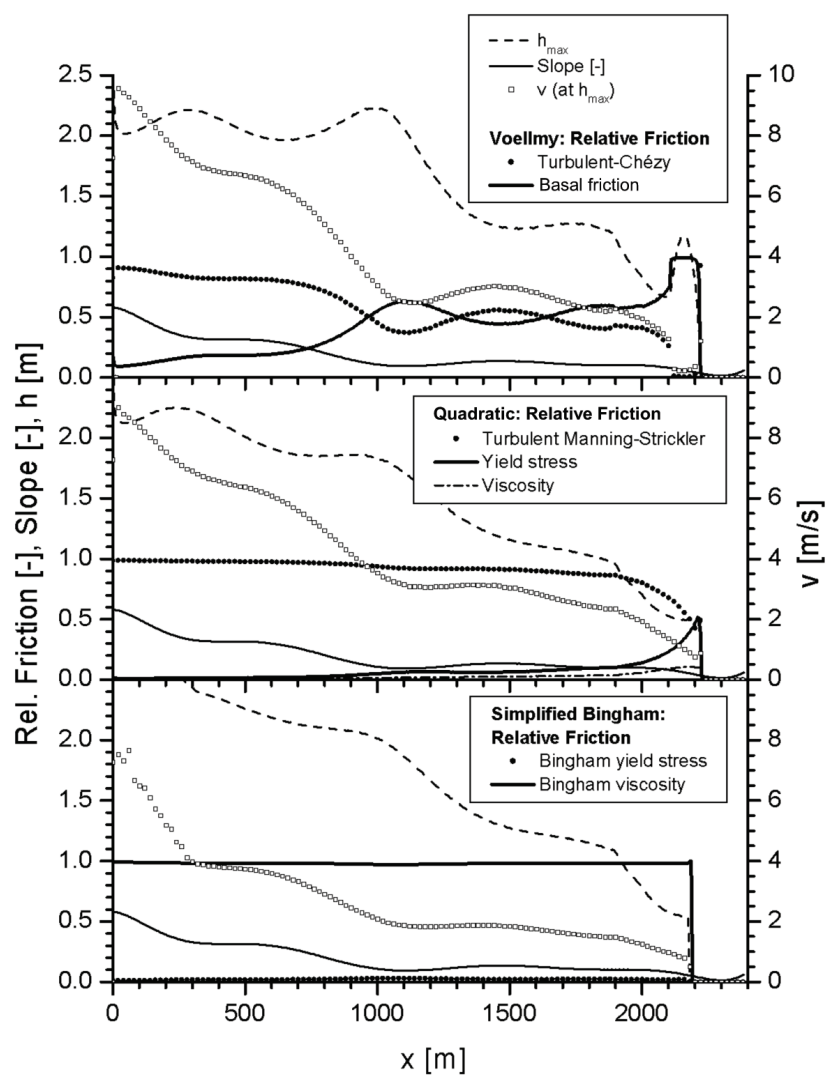

Fig. 6. Magnitude of flow resistance terms of for the Voellmy (Table 1, C), Quadratic (I), and simplified Bingham (B) laws.

of the flow. For flow resistance relation E (Table 1), the yield stress contribution to the total flow resistance is similar to the sum of yield stress and viscosity contribution in the quadratic flow resistance relation.

A comparison of the discharge hydrographs (at $x=1590 \mathrm{~m}$ ) among the field and simulations (Fig. 7) shows systematic differences. In particular, the peak discharge is underpredicted and field hydrograph changes much more rapidly than in the simulated results. Similar behavior has also been found using other simulation models, suggesting a systematic deficiency in the ability of such simple flow resistance relations to represent all features of debris flows. One practical solution to this problem is to iteratively run the simulations with a relatively large discharge to match the peak discharge where it is measured (e.g. McArdell et al., 2003).

\section{Discussion}

The DFEM-1D model is based on a one-phase flow approach to approximate the flow resistance behavior of mixtures of sediment and water. Because the values of the flow resistance coefficients depend on many factors and can be expected to vary among different debris flows, calibration with historical events in the same catchment or with flows in nearby catch-

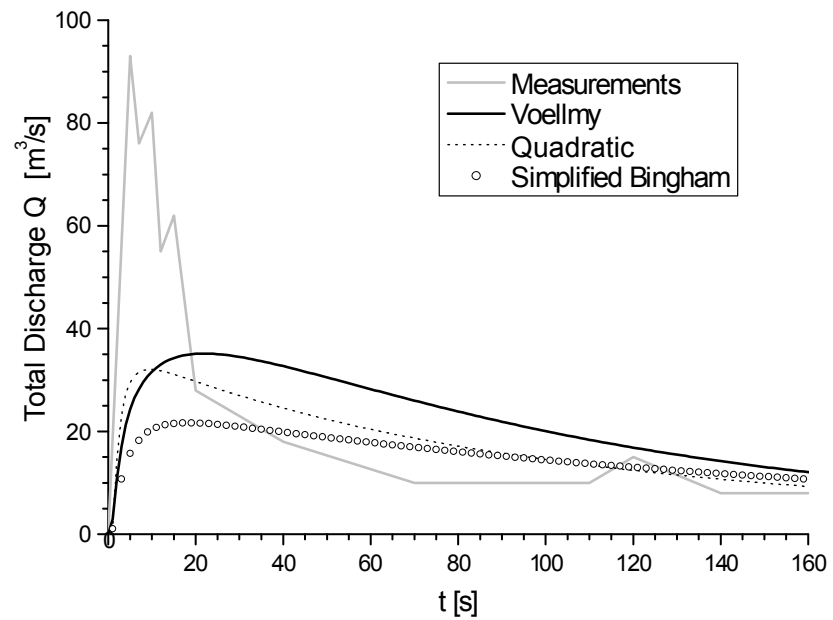

Fig. 7. Measured and simulated total discharges at $\mathrm{x}=1590 \mathrm{~m}$ for flow resistance relations presented in Fig. 6.

ments is essential. The rheological coefficients can in some cases be estimated with field observations (e.g. Laigle et al., 2003) or in the laboratory (Coussot et al., 1998). The singlephase approach to describe debris flows ignores experimental evidence of dynamic pressures arising from the grain collisions in granular flows (Iverson, 1997) which suggests that rheological relations that do not include such normal stress effects are an oversimplification. However, as pointed out by Hungr (2006) intergranular friction forces may implicitly be accounted for in the frictional and velocity-dependent flow resistance terms.

Our model underpredicted flow depths when calibrated for runout distance. In a similar study (Rickenmann et al., 2003), model parameters were iteratively calculated by successive model runs to obtain a good match between total runout distance and observed flow velocities, however flow depths were also generally underestimated by up to a factor of 2 . Using the DFEM-1D model, observed and simulated flow depths in the channel are generally difficult to compare because a rectangular cross sectional area is used in the model. For designing protection measures or safety analysis of the capacity of a given cross section, especially when the crosssection is not rectangular, it is more useful to compare the wetted cross sectional area than flow depth.

Constant flow resistance parameters were assumed over time and along the debris-flow wave; even though better results are likely if the coefficients were varied as a function of distance along the wave (e.g. Hungr, 2000) or distance along the channel to better match, for example, the observed hydrograph. Savage and Iverson (2003) show that an increased pore-pressure diffusivity in the snout region (related to accumulation of large particles) can increase solid bed friction and cause the more mobile rear part of the flow to pile up against the snout region. It appears therefore possible that a more realistic model accounting for non-homogeneous flow properties, particularly in the front region, could better 
replicate the observed flow behavior (e.g. resulting in higher flow depth and peak discharge). In principle one could indirectly account for longitudinal particle segregation and differences in sediment concentration by varying the flow resistance parameters along the debris-flow wave, thereby improving flow depth estimates. However such an exercise introduces more model parameters and a larger uncertainty in their "calibration".

In many field examples, systematic bulking of the debris flow influences the results (Hungr et al., 2005); these processes are not yet included in the DFEM-1D model. Incorporation of entrainment (and deposition) effects into a model should be included in a more general framework where the level of the bed can also be adjusted to reflect these processes. For example, Hungr and Evans (1997), Brufau et al. (2000) and McDougall and Hungr (2006) developed models including some of these aspects in a simplified manner.

For the field case application presented here, models involving turbulent flow resistance terms appear to behave more realistically (e.g. better agreement with flow depth, velocity, and runout distance) than the other flow resistance relations. A similar study involving more test cases (Rickenmann et al., 2003) showed similar findings and furthermore suggested that Voellmy fluid relation is convenient from a numerical stability perspective. Similarly, the quadratic relation tends to produce reasonable results in many situations. However, three parameters need to be calibrated for the application of the quadratic relation, in contrast to two parameters for the Voellmy relation.

As of yet there is no simple model which can correctly reproduce all of the complex features of debris flow behavior. Along the flow path the material properties and channel roughness most likely vary. Another major difficulty for simulating natural debris flows is distinguishing between appropriate flow regimes and suitable modeling approaches. While two-phase models describing the complex interaction between solids and fluids exist and are in development (e.g. Bozhinskiy and Nazarov, 2000; Iverson and Denlinger, 2001), they also require knowledge of parameters that are difficult to measure and may require calibration, such as the sediment concentration which may vary over a considerable range (e.g. 40 to $90 \%$ by weight, Costa 1984).

For a debris-flow hazard assessment where a model is used as a decision-making or a design tool, it may be reasonable in a first step to estimate the total event volume (or design volume) and apply a one-phase model to delineate potentially affected areas, especially if field data from the catchment can be used to calibrate the flow resistance coefficients. When comparing model simulation results with observations of natural debris flows, it is often possible to achieve a reasonable agreement between some of the predicted and observed characteristics (e.g. Jakob et al., 2000; Revellino et al., 2004; Rickenmann et al., 2006). Referring to Fig. $1 \mathrm{~b}$ it is remarkable that quite similar deposition profiles are obtained for different rheologic approaches or flow resistance laws when simulating similar runout lengths. This observation supports the results presented in Rickenmann et al. (2006), where similar deposition patterns were modeled using debris-flow simulation models based on different rheological approaches. In many cases only the event volume and the runout distance or the deposition pattern is known, possibly supplemented by the rheologic analysis of material samples. In other cases there may be limited flow velocity and depth data from measurements or eyewitness accounts. Therefore most of the existing models have not been thoroughly tested with field data. In addition, no simple methods are available to directly determine the rheologic parameters which are needed as input for most of the models mentioned above.

\section{Conclusions}

The simulation code DFEM-1D, based on a solution to the shallow water equations and including a simple treatment of the wet-dry boundary at the front of the flow, facilitates the comparison of a variety of single-phase flow resistance relations which have been proposed for debris flows. We find good agreement with the analytical solution of a dam-break wave. For application to field cases, it is essential to calibrate such models (e.g. the coefficients in the flow resistance relations) using historical events. Comparing the calculated front trajectories for a granular debris flow at the Kamikamihori valley in Japan, the best agreement is obtained for approaches including a turbulent flow resistance term; the other approaches, including Bingham and dilatant fluids, tend to underpredict observed front velocities. Although it is possible to reasonably match the front trajectory of the flow, we observe a general tendency for the model to underpredict the flow depth or discharge when the model is calibrated using runout and velocity data. This problem seems to be common in the application of models based on the single-phase approach.

The relative importance of the flow resistance terms along the flow path was compared among three flow resistance relations. The stopping term includes the basal friction angle for the Voellmy fluid, and the yield stress for the quadratic or simplified Bingham approach. In the latter two cases, the yield stress contribution is important only in the final stopping phase. For the Voellmy fluid, a significant contribution of the basal friction angle $\delta$ to the total resistance is found when channel slope angles are about $2 \delta$ or less.

The sensitivity to the input hydrograph was investigated using the Voellmy relation. Varying the shape of the input hydrograph for equal volumes, we found that differences in peak discharge are dampened within about the first kilometer of the flow path, resulting in only small differences over the downstream reaches. Model runout distances are, however, quite sensitive to the total input volume, even when the initial peak discharge is held constant. 
Based also on experience from other studies using similar modeling approaches, it appears that some general debris flow characteristics needed for hazard assessment may be reasonably well simulated with rather simple modeling approaches if an a priori calibration of the model parameters is possible.

Acknowledgements. This work was partially funded by the European Union THARMIT project (Torrent Hazard Control in the European Alps: Practical tools and methodologies for hazard assessment and risk mitigation) under contract No.: EVG1CT-1999-00012. We are grateful to our colleagues at WSL, C. Graf and M. Swartz, for their help and comments during this work.

Edited by: F. Guzzetti

Reviewed by: O. Hungr, B. Zanuttigh, and another referee

\section{References}

Ancey, C. and Jorrot, H.: Yield stress for particle suspensions within a clay dispersion, J. Rheol., 45(2), 297-319, 2001.

Arattano, M. and Franzi, L.: Analysis of different water-sediment flow processes in a mountain torrent, Nat. Hazards Earth Syst. Sci., 4, 783-791, 2004.

Bartelt, P., Salm, B., and Gruber, U.: Calculating densesnow avalanche runout using a Voellmy-fluid model with active/passive longitudinal straining, J. Glaciol., 45(150), 242-254, 1999.

Bechteler, W., Nujic, M., and Otto, A. J.: Calculation of 2d flood propagation using the program package FLOODSIM, in: Modelling of flood propagation over initially dry areas, Milan, 257267, 1994.

Bozhinskiy, A. N. and Nazarov, A. N.: Two-phase model of debris flow, in: Proc. 2nd Int. Conf. on Debris-Flow Hazards Mitigation: Mechanics, Prediction, and Assessment, Taipei, Taiwan, edited by: Wieczorek, G. F. and Naeser, N. D., Balkema, Rotterdam, 263-269, 2000.

Brufau, P., Garcia-Navarro, P., Ghilardi, P., Natale, L., and Savi, F.: 1D mathematical modelling of debris flow, J. Hydrol. Res., 38(6), 435-446, 2000.

Chen, C.-L.: Generalized viscoplastic modeling of debris flow, J. Hydrol. Eng., 114(3), 237-258, 1988.

Chen, H. and Lee, C. F.: A dynamic model for rainfall-induced landslides on natural slopes, Geomorphology, 51(4), 269-288, 2003.

Chuang, M.-H., Chang, T.-J., Hsu, M.-H., and Lin, M.-L.: An analysis of debris-flow transport in tributaries of Chen-Yo-Lan creek, Taiwan, Proc. 2nd Int. Conf. on Debris-Flow Hazards Mitigation: Mechanics, Prediction, and Assessment, Taipei, Taiwan, edited by: Wieczorek, G. F. and Naeser, N. D., Balkema, Rotterdam, 515-519, 2000.

Contreras, S. M. and Davies, T. R. H.: Hysteresis and timedependent rheology of debris-flow material, J. Hydrol. Eng., 126(12), 938-941, 2000.

Costa, J. E.: Physical geomorphology of debris flows, SpringerVerlag, Berlin, 1984.

Costa, J. E.: Hydraulic modeling for Lahar hazards at Cascades Volcanoes, Environmental \& Engineering Geoscience, III(1), 21-30, 1997.
Coussot, P.: Mudflow rheology and dynamics, A. A. Balkema, Rotterdam, 1997.

Coussot, P., Laigle, D., Arattano, M., Deganutti, A., and Marchi, L.: Direct determination of rheological characteristics of debris flow, J. Hydrol. Eng., 124(8), 865-868, 1998.

Crosta, G. B. Chen, H., and Lee, C. F.: Replay of the 1987 Val Pola Landslide, Italian Alps, Geomorphology, 60(1-2), 127-146, 2004.

Fraccarollo, L. and Papa, M.: Numerical Simulation of Real DebrisFlow Events, Physics and Chemistry of the Earth, Part B: Hydrology, Oceans and Atmosphere, 25(9), 757-763, 2000.

Ghilardi, P., Natale, L., and Savi, F.: Debris-flow propagation on urbanized alluvial fans, Proc. 2nd Int. Conf. on Debris-Flow Hazards Mitigation: Mechanics, Prediction, and Assessment, Taipei, Taiwan, edited by: Wieczorek, G. F. and Naeser, N. D., Balkema, Rotterdam, 471-477, 2000.

Han, G. and Wang, D.: Numerical modeling of Anhui debris flow, J. Hydrol. Eng., 122(5), 262-265, 1996.

Hashimoto, H.: A comparison between gravity flows of dry sand and sand-water mixtures, Recent Developments on Debris Flows, A. Armanini and M. Michiue, eds., Springer, New York, 70-92, 1997.

Hübl, J. and Steinwendtner, H.: Zweidimensionale Modellierung von Murgängen anhand zweier ausgewählter Beispiele in Oesterreich, Proc. Int. Symp. Interpraevent, Villach/Österreich, 179190, 2000.

Hungr, O.: A model for the runout analysis of rapid flows slides, debris flows, and avalanches, Canadian Geotechnical Journal, 32(4), 610-623, 1995.

Hungr, O.: Analysis of debris flow surges using the theory of uniformly progressive flow, Earth Surf. Proc. Landf., 25, 483-495, 2000.

Hungr, O.: Rock avalanche occurrence, process and modelling, Keynote Paper, in: NATO Advanced Workshop on Massive Slope Failure, Celano, Italy, edited by: Evans, S. G., ScarasciaMugnozza, G., Strom, A., and Hermanns, R., Springer, Heidelberg, in press, 2006.

Hungr, O. and Evans, S. G.: A dynamic model for landslides with changing mass, Proc. Engineering Geology and the Environment, Athens, Greece, 719-724, 1997.

Hungr, O., McDougall, S., and Bovis, M.: Entrainment of material by debris flows, in: Debris-Fow Hazards and Related Phenomena, edited by: Jakob, M. and Hungr, O., Praxis-Springer, 135-158, 2005.

Hürlimann, M., Rickenmann, D., and Graf, C.: Field and monitoring data of debris-flow events in the Swiss Alps, Canadian Geotechnical Journal, 40(1), 161-175, 2003.

Imran, J., Parker, G., Locat, J., and Lee, H.: 1D Numerical model of muddy subaqueous and subaerial debris flows, J. Hydr. Eng., 127(11), 959-967, 2001.

Iverson, R. M.: The physics of debris flows, Rev. Geophys., 35(3), 245-296, 1997.

Iverson, R. M. and Denlinger, R. P.: Flow of variably fluidized granular masses across three-dimensional terrain 1 . Coulomb mixture theory, J. Geophys. Res., 106(B1), 537-552, 2001.

Jakob, M., Anderson, D., Fuller, T., Hungr, O., and Ayotte, D.: An unusually large debris flow at Hummingbird Creek, Mara Lake, British Columbia, Canadian Geotechnical Journal, 37, 1109$1125,2000$. 
Jan, C.-D. and Shen, H. W.: Review Dynamic Modeling of Debris Flows, In: Recent developments on debris flows, edited by: Armanini, A. and Michiue, M., Springer, 93-113, 1997.

Jin, M. and Fread, D. L.: 1D modeling of mud/debris unsteady flows, J. Hydrol. Eng., 125(8), 827-834, 1999.

Johnson, A. M. and Rodine, J. R.: Debris flow, in: Slope Stability, edited by: Brundsen, D. and Prior, D. B., 257-361, 1984.

Julien, P.: Introduction to Chapter 2 on Dynamics of debris flow, in: Recent developments on debris flows, edited by: Armanini, A. and Michiue, M., Springer, 65-69, 1997.

Julien, P. and Lan, Y.: Rheology of hyperconcentrations, J. Hydrol. Eng., 117(3), 346-353, 1991.

Katopodes, N. D.: Two-dimensional surges and shocks in open channels, J. Hydrol. Eng., 110(6), 794-812, 1984.

Koch, T.: Simulationsrechnungen zu Murgängen: 1-D Modelle und deren Anwendung, WSL, Birmensdorf, 1998.

Laigle, D. and Coussot, P.: Numerical modeling of mudflows, J. Hydrol. Eng., 123(7), 617-623, 1997.

Laigle, D., Hector, A.-F., Hübl, J., and Rickenmann, D.: Comparison of numerical simulation of muddy debris-flow spreading to records of real events, in: Proc. 3rd Int. Conf. on Debris-Flow Hazards Mitigation: Mechanics, Prediction, and Assessment, Davos, Switzerland, edited by: Rickenmann, D. and Chen, C. L., Millpress, Rotterdam, 635-646, 2003.

Malet, J. P., Remaître, A., Maquaire, O., Ancey, C., and Locat, J.: Flow susceptibility of heterogeneous marly formations: implications for torrent hazard control in the Barcelonnette Basin (Alpes-de-Haute-Provence, France), in: Proc. 3rd Int. Conf. on Debris-Flow Hazards Mitigation: Mechanics, Prediction, and Assessment, Davos, Switzerland, edited by: Rickenmann, D. and Chen, C. L., Millpress, Rotterdam, 351-362, 2003.

McArdell, B. W., Zanuttigh, B., Lamberti, A., and Rickenmann, D.: Systematic comparison of debris flow laws at the Illgraben torrent, Switzerland, in: Proc. 3rd Int. Conf. on Debris-Flow Hazards Mitigation: Mechanics, Prediction, and Assessment, Davos, Switzerland, edited by: Rickenmann, D. and Chen, C. L., Millpress, Rotterdam, 647-657, 2003.

McDougall, S. and Hungr, O.: Dynamic modelling of entrainment in rapid landslides. Can. Geotech. J. 42(5), 1437-1448, 2005.

Naef, D. R.: Numerische Simulation von Stosswellen in Freispiegelströmungen, Mitteilungen Versuchsanstalt für Wasserbau, Hydrologie und Glaziologie, ETH Zürich, Nr. 148, 1997.

Nakagawa, H. and Takahashi, T.: Estimation of a debris flow hydrograph and hazard area, Proc. 1st Int. Conf. on Debris Flow Hazards Mitigation: Mechanics, Prediction, and Assessment, San Francisco, CA, USA, 64-73, 1997.

Nujic, M.: Efficient implementation of non-oscillatory schemes for the computation of free-surface flows, J. Hydr. Res. 35(1), 101$111,1995$.

O’Brien, J. S., Julien, P. Y., and Fullerton, W. T.: Two-dimensional water flood and mudflow simulation, J. Hydrol. Eng., 119(2), 244-261, 1993.

Okuda, S., Suwa, H., Okunishi, K., Yokoyama, K., and Nakana, M.: Observations on the motion of a debris flow and its geomorphological effects, Zeitschrift Geomorph. N.F., Suppl. Bd., 35, 142-163, 1980.

Pierson, T. C., and Costa, J. E.: A rheologic classification of subaerial sediment-water flow, Geol. Soc. Am., Rev. Eng. Geol., 7,
1-12, 1987.

Revellino, P., Hungr, O., Guadagno, F. M., and Evans, S. G.: Velocity and runout simulation of destructive debris flows and debris avalanches in pyroclastic deposits, Campania region, Italy, Environmental Geology, 45(3), 295-311, 2004.

Rickenmann, D.: Bedload transport capacity of slurry flows at steep slopes, Mitteilungen Versuchsanstalt für Wasserbau, Hydrologie und Glaziologie, ETH Zürich, 103, 1990.

Rickenmann, D.: Empirical relationships for debris flows, Natural Hazards, 19(1), 47-77, 1999.

Rickenmann, D. and Koch, T.: Comparison of debris flow modeling approaches, in: Proc. 1st Int. Conf. on Debris-Flow Hazards Mitigation: Mechanics, Prediction, and Assessment, San Francisco, CA, USA, edited by: Chen, C. L., American Society of Civil Engineers, New York, 576-585, 1997.

Rickenmann, D., Laigle, D., Lamberti, A., Zanuttigh, B., Armanini, A., Fraccarollo, L., Giuliani, M., Rosati, G., McArdell, B. W., Naef, D., Swartz, M., and Graf, C.: Evaluation of existing numerical simulation models for debris flows, Report on work package 3 of the research project THARMIT of the European Union, E.U. Contract EVG1-CT-1999-00012, 2003.

Rickenmann, D., Laigle, D., McArdell, B. W., and Hübl. J.: Comparison of 2D debris-flow simulation models with field events, Computational Geosciences, special issue 10/1, in press, doi:10.1007/s10596-005-9021-3, 2006.

Rutschmann, P.: FE solver with 4d finite elements in space and time, Proc. 8th Int. Conf. on Finite Elements in Fluids, Barcelona, 136-144, 1993.

Rutschmann, P.: Obtaining higher order accuracy with linear shape functions - A new approach for transient problems, Proc. Computational Fluid Dynamics 1994, 165-169, 1994.

Savage, S. B. and Iverson, R. M.: Surge dynamics coupled to porepressure evolution in debris flows, in: Proc. 3rd Int. Conf. on Debris-Flow Hazards Mitigation: Mechanics, Prediction, and Assessment, Davos, Switzerland, edited by: Rickenmann, D. and Chen, C. L., Millpress, Rotterdam, 503-514, 2003.

Shieh, C.-L., Jan, C.-D., and Tsai, Y.-F.: A numerical simulation of debris flow and its application, Natural Hazards, 13(1), 39-54, 1996.

Suwa, H.: Field observation of debris flow, Proc. Japan-China (Taipei) Joint Seminar on Natural Hazard Mitigation, Kyoto, Japan, 343-352, 1989.

Suwa, H. and Okuda, S.: Deposition of debris flows on a fan surface, Mt. Yakedake, Japan, Zeitschrift Geomorph. N. F., Suppl. Bd. 46, 79-101, 1983.

Takahashi, T.: Debris Flow, A. A. Balkema, Rotterdam, 1991.

Takahashi, T.: Initiation and flow of various types of debris-flow, in: Proc. 2nd Int. Conf. on Debris-Flow Hazards Mitigation: Mechanics, Prediction, and Assessment, Taipei, Taiwan, edited by: Wieczorek, G. F. and Naeser, N. D., Balkema, Rotterdam, 15-25, 2000.

Takahashi, T.: Mechanics and simulation of snow avalanches, pyroclastic flows and debris flows, in: Particulate Gravity Currents. Spec. Publ. Int. Ass. Sedimentologists, 31, 11-43, 2001.

Zanuttigh, B. and Lamberti, A.: Analysis of debris wave development with one-dimensional shallow-water equations, J. Hydrol. Eng., 130(4), 293-304, 2004. 